\title{
Association of the connexin36 gene with juvenile myoclonic epilepsy
}

\author{
C Mas, N Taske*, S Deutsch*, M Guipponi, P Thomas, A Covanis, M Friis, M J Kjeldsen, \\ G P Pizzolato, J-G Villemure, C Buresi, M Rees, A Malafosse, M Gardiner, S E Antonarakis, \\ P Meda
}

J Med Genet 2004;41:e93 (http://www.jmedgenet.com/cgi/content/full/41/7/e93). doi: 10.1136/jmg.2003.017954

ए pilepsy is one of the most common and serious neurological disorders, with up to 60 million people affected worldwide. ${ }^{1}$ Juvenile myoclonic epilepsy (JME) is a common familial form that accounts for $5-10 \%$ of all epilepsy cases. ${ }^{2}$ This form belongs to the idiopathic epilepsy group, due to the absence of detectable structural or metabolic abnormalities. Clinically, JME is mainly characterised by isolated myoclonic jerks on awakening that usually begin during adolescence. It is also highly drug-dependent, since a $90 \%$ recurrence is reported after interruption of pharmacological treatment. ${ }^{3}$

Studies on the incidence of epilepsy in relatives of probands with JME, as well as on twins, have provided strong evidence for a genetic contribution. ${ }^{45}$ Autosomal dominant, autosomal recessive, two locus, monogenic, and polygenic models of inheritance have been suggested. ${ }^{6}$ So far, three genes that are mutated in different forms of JME have been identified, namely CACNB4, ${ }^{7}$ GABRA1, ${ }^{8}$ and $C L C N 2 .{ }^{9}$ In addition, two different susceptibility loci have been identified by linkage analysis. The first locus, termed EJMI (OMIM 254770), is on the human leukocyte antigen region of chromosome $6 \mathrm{p} .{ }^{10}$ Although no trait-causing mutation has yet been identified at this locus, association with a haplotype of the BRD2 gene has been recently reported. ${ }^{11}$ The second locus, termed EJM2 (OMIM 604827), is in the region of chromosome 15q that contains the gene coding for the $\alpha 7$ nicotinic acetylcholine receptor subunit. Genetic mapping of the EJM2 locus defined a $15.1 \mathrm{cM}$ candidate region on chromosome 15q14, flanked by the D15S165 and D15S971 loci. ${ }^{6}$ Interestingly, this region includes the $C X 36$ gene, which codes for the first connexin identified in neurons. ${ }^{12}$

Connexins are integral membrane proteins, encoded by a family of at least 20 genes in humans, which form the subunits of gap junction channels. ${ }^{13}$ Gap junctions permit the cell-to-cell passage of ions, second messengers, and small metabolites and, in the nervous system, provide the structural basis of electrical synapses. ${ }^{14}$ Several studies indicate the relevance of gap junction-mediated coupling in maintaining the synchronous activity of neuronal populations, and the gamma frequency oscillations which are thought to underlie a range of cognitive processes. ${ }^{15}{ }^{16}$ Thus, recordings between fast-spiking cells of neocortex has revealed a high occurrence of electrical coupling, ${ }^{17}$ suggesting that electrical and synaptic coupling act synergistically to improve neuronal synchronisation. ${ }^{18}$ Accordingly, deletion of CX36 in mice results in loss of electrical synapses, preventing the synchronous inhibitory activities which underlie gamma oscillations in the cerebral cortex. ${ }^{19}{ }^{20}$ Further experiments have revealed that expression of $C \times 36$ is markedly reduced in the hippocampus of kindled and kainate-treated rats, an animal model of human temporal epilepsy. ${ }^{21}$

These observations, together with the location of the CX36 gene on human chromosome 15q14, make this gene a strong

\section{Key points}

- Juvenile myoclonic epilepsy (JME) is a generalised form of epilepsy with onset in early adolescence. Genetic factors are likely to play a role in the etiology of JME, and significant evidence supports a major susceptibility locus located on chromosome 15q14, where the gene connexin36 (CX36) is also mapped. Since electrotonic communication between neurons connected by gap junctions is likely to be implicated in the generation and maintenance of neuronal synchrony, mutations in the CX36 gene may be associated with JME.

- Mutation analysis of the human CX36 gene was undertaken in 29 probands from JME families previously linked to the $15 q 14$ locus, as well as in 17 randomly selected (RS) JME patients. Sequencing identified five single nucleotide polymorphisms (SNPs), c. $-127 \mathrm{~A}>\mathrm{T}$, с. $333 \mathrm{~T}>\mathrm{A}$, c. $369 \mathrm{C}>\mathrm{T}$, c. $588 \mathrm{C}>\mathrm{T}$, and c. $888 \mathrm{G}>\mathrm{A}$, none of which resulted in an amino acid substitution.

- A case control study performed on a sample of 29 15q14-linked JME patients, 140 RS JME patients, and 123 controls, demonstrated a significant association between JME and the c.588C $>$ T polymorphism within exon 2, with significant differences in both allele $(p=0.03)$ and genotype $(p=0.017)$ frequencies. Subjects with the T/T genotype at position 588 had a significantly increased risk of JME lodds ratio 4.3; $95 \%$ Cl 1.49 to 12.3), compared with those with a $\mathrm{C} / \mathrm{C}$ genotype. In addition, HAP2, a haplotype containing c.588C $>\mathrm{T}$, was found to be significantly associated with JME ( $p=0.03)$.

- Further analysis suggested that the c.588C $>\mathrm{T}$ polymorphism may influence $\mathrm{C} \times 36$ gene expression by affecting exonic splicing enhancers. This defect may contribute to the pathogenesis of JME.

candidate for JME. To test this hypothesis, we searched for mutations in the coding regions and intron-exon junctions of CX36 in most of the European cases of 15q14-linked and in randomly selected (RS) JME patients. We found that these patients had no mutation in the coding regions of $C X 36$. However, several single nucleotide polymorphisms (SNPs)

Abbreviations: CEPH, Centre d'Etude du Polymorphisme Humain; ESE, exonic splicing enhancer; HW, Hardy-Weinberg; ILAE, International League Against Epilepsy; JME, juvenile myoclonic epilepsy; LD, linkage disequilibrium; RS, randomly selected; SNP, single nucleotide polymorphism 
were identified, one of which had allelic frequencies statistically different from those of controls. Moreover, a haplotype of $C X 36$ appeared to be over represented in JME patients. The results provide the first evidence for an association between CX36 and the 15q14-linked JME families.

\section{METHODS}

\section{Cases and control sample}

A total of 169 patients with JME were investigated: 29 of these were unrelated individuals from the families used to identify the 15 q14 susceptibility locus, ${ }^{6}$ whereas the other 140 patients were RS from the neurology departments of five hospitals, irrespective of whether an epileptic syndrome affected first degree relatives or not. ${ }^{22}$ The majority of the 15q14-linked patients (2/3) were clinically ascertained from within the UK, the others originating from five other European countries (Denmark, France, Greece, Portugal, and Sweden). Diagnostic evaluation was made according to the classification of the International League Against Epilepsy (ILAE). The control group included unrelated individuals who were randomly selected from families of the Centre d'Etude du Polymorphisme Humain (CEPH) $(n=44)$, and of the Swiss population $(n=79)$. SNP c.333T $>$ A was further genotyped on 94 additional Swiss controls. Since allele frequency and distribution of both genotypes and haplotypes were similar in CEPH and Swiss controls, these two sub-populations were combined into a single control group, comprising 123 individuals $(50 \%$ women). Informed consent was obtained from all participating individuals, and the study was approved by the ethic committees of all participating institutions (National Hospital for Neurology and Neurosurgery, London; Paris Hospital Ethics Committee; and Ethical Committee of the Geneva University Hospital).

\section{Mutation analysis and identification of SNPs}

Detection of mutation was performed by genomic PCR amplification and direct sequencing. We designed primers using the human genomic sequences (GenBank AC012271) which encompass $C X 36$. Primer pairs were selected to amplify fragments covering the whole coding region of this gene, all intron-exon junctions, and $572 \mathrm{bp}$ of the $5^{\prime}$ UTR. Primers sequences were 5'TAAAAGGAAAGGGGGATTCG3' and 5'CT CAGTCCAGGTGTGAGAAGG3' for exon 1; 5'CAGCTCCCCA GTCAAAAGAC3' and 5'GGTCACATAAATGAGGGTGGA3' for exon 2; 5'ACGCAGGCGGAGACTACTTA3' and 5'CCCGATCA TAGTGGAGTGCT3' for the 5'UTR. Amplification reaction was performed with $100 \mathrm{ng}$ total genomic DNA. The $25 \mu \mathrm{l}$ PCR mixture contained $250 \mu \mathrm{M}$ deoxynucleotide triphosphates, $200 \mathrm{nM}$ each primer, $2.5 \mu \mathrm{l} 10 \times$ PCR buffer (Finnzymes), and $1.25 \mathrm{U}$ Dynazime Taq polymerase (Finnzymes, Espoo, Finland). All samples were amplified in a T Gradient Thermocycler 96 (Biometra, Germany), under the following conditions: initial denaturation at $94^{\circ} \mathrm{C}$ for $4 \mathrm{~min}$, followed by 35 cycles of denaturation at $94^{\circ} \mathrm{C}$ for $30 \mathrm{~s}$, annealing at $60^{\circ} \mathrm{C}$ for $40 \mathrm{~s}$, and extension at $72^{\circ} \mathrm{C}$ for $1 \mathrm{~min}$. After purification, the PCR products were sequenced using standard protocols, an ABI 377 automated sequencer, and an additional primer for exon 2 (5'CACCAGTCCGCCAAGCAG CGAG3'). Chromatographs of amplicons from affected individuals were compared to the genomic sequence of the CX36 gene using the gap4 editor, which is available at the UK HGMP Resource Centre (http://www.hgmp.mrc.ac.uk). Five SNPs were characterised and named with reference to the CX36 cDNA sequence (GenBank NM_020660).

\section{SNP genotyping}

Selected regions encompassing each identified SNP were amplified from genomic CX36 DNA and analysed by pyrosequencing. The following PCR primer pairs were employed (b indicates biotin): 5'GGTCGGGACGCGCTTGGA TTT3' and 5'bCCCCCTGACCGCCGGCTT3' for c.-127A $>$ T (expected amplicon $258 \mathrm{bp}$ ); 5'CCTACTCTGTGCACCAGTC CG3' and 5'bCCCCATTCACAATAGCATTT3' for c.333T>A and c.369C $>$ T (expected amplicon $174 \mathrm{bp}$ ); 5'bACTCCACA CCCATCAGGTCTA3' and 5'CGGAACACCACTTGGATAAT3' for c.588C $>$ T (expected amplicon $95 \mathrm{bp}$ ); 5'bCTCAACCTGG CTGAACTCAAC3' and 5'CCCAGACCTTCATGAAACCTG3' for c.888G $>$ A (expected amplicon $194 \mathrm{bp}$ ). The corresponding sequencing primers were: 5'GATTCGAGGATTTTTT3', 5'GAA CGCCGCTACTCT3'， 5'AGACCCCCCTGAGTC3'， 5'GGCAGGA AGGCATCTC3', and 5'CAGGTCCTTGTTACGAAT3', respectively.

All amplification reactions were carried out in a 96 well microtitre plate thermal cycler (Biometra, Germany), under the same conditions used for the mutation analysis. Preparation of single-strand DNA and annealing to the sequencing oligonucleotide were as reported. ${ }^{23}$ Briefly, attachment of the biotinylated DNA amplicon to streptavidin-modified paramagnetic beads was followed by a high salt washing step, a $10 \mathrm{~min} \mathrm{NaOH}(0.15 \mathrm{M})$ denaturation step, and a final annealing step $\left(95^{\circ} \mathrm{C}, 15 \mathrm{~s}\right)$. Purified fragments annealed with the cognate sequencing primers were then processed for sequencing. DNA mini-sequencing was performed using a PSQ96 instrument, enzymes, and dNTPS (all from Pyrosequencing $\mathrm{AB}$ ), as previously described. ${ }^{23}$ All the resulting genotypes, which were automatically assigned to the samples by the SNP analysis software, were checked by two independent investigators.

\section{Statistical analysis}

The extent of linkage disequilibrium (LD) of each SNP combination was assessed in all 123 control individuals, by calculating $\mathrm{r}^{2}$ using a DNA sequence polymorphism program. ${ }^{24} \mathrm{~A}$ two-tailed Fisher's exact test and the Bonferroni procedure were computed to determine the significance of association between polymorphic sites. Five-SNP-locus haplotypes were inferred from genotypes of the control group, using the Bayesian method, ${ }^{25}$ as provided by PHASE software. The algorithm deals with missing genotype data, so that a total of 246 haplotypes were inferred in the control group. Similarly, haplotypes of both control and JME groups were inferred for the four SNPs which were selected after LD analysis, for subsequent case control analysis. CX36 haplotype genealogies were constructed using the reduced-mediannetwork approach, available in Network 3.1 software (Fluxus-engineering; www.fluxus-engineering.com). HardyWeinberg (HW) equilibrium was tested for each SNP using the HW exact test, as implemented in Genepop software (http://wbiomed.curtin.edu.au/genepop). Logistic regression models were used to calculate odds ratios (OR, 95\% confidential interval). The Fisher's exact test was used for contingency table inference. To correct for multiple comparisons, we used a modified Bonferroni test as described in Sankoh et al, ${ }^{26}$ which accounts for the level of correlation between linked markers. In this case, p values $\leqslant 0.019$ were taken to indicate a significant difference for $\alpha=0.05$. For haplotype associations no correction is required and $\mathrm{p}$ values $\leqslant 0.05$ were considered to indicate statistically significant difference.

\section{RESULTS}

\section{CX36 mutation screening}

A total of 46 JME patients, including 29 individuals whose pedigrees had previously been used to determine the $15 \mathrm{ql} 4$ susceptibility locus, and 17 RS JME patients, were screened for mutations of CX36, as compared to four unaffected controls. Screening of the whole coding region, 
the intron-exons junctions, $48 \mathrm{bp}$ of the splice donor, $70 \mathrm{bp}$ of the intron splice-acceptor sites, and $70 \mathrm{bp}$ of the $3^{\prime}$ untranslated region revealed no mutation of the $C X 36$ gene in JME patients which could result in an amino acid substitution or affect the splicing and branching sites of RNA.

\section{Polymorphisms}

Four SNPs were detected in CX36 exon 2 (table 1). One was a $\mathrm{T}>\mathrm{A}$ transversion (c.333T $>\mathrm{A}$ ), and the three others included a $\mathrm{G}>\mathrm{A}$ transition (c.888G $>\mathrm{A}$ ) and two $\mathrm{C}>\mathrm{T}$ transitions (c.369C $>$ T; c. 588C $>$ T), respectively. An additional SNP was identified in the $5^{\prime}$-untranslated region (5'UTR) of the $C X 36$ and involved an $\mathrm{A}>\mathrm{T}$ transversion located $127 \mathrm{bp}$ upstream of the translation initiation codon (c.-127A $>$ T).

\section{Characterisation of SNP genotypes and haplotypes}

The allele frequencies of the five CX36 SNPs were determined in a control group of 123 individuals (table 1). Genotype frequencies for all SNPs were in HW equilibrium (not shown). Haplotypic combinations of the five SNPs are shown in fig l. A total of eight out of the 32 possible haplotypes were observed. The most common HAPl haplotype, which represents $>30 \%$ of all haplotypes, was found to be conserved in non-human primates (fig 1), suggesting that it most likely represents the ancestral haplotype. To explore the evolution of the CX36 gene, sequence genealogies were constructed, using a method that equally weighted all nucleotide positions. The skeleton network revealed two major branches in the northern European CX36 genealogy (HAP4 and HAP5 accounting for $>30 \%$ of all haplotypes, and HAP2 and HAP6 accounting for $>25 \%$ ), which had evolved from a unique ancestral haplotype (HAPl), via two successive mutations events (fig 1).

\section{Linkage disequilibrium analysis}

Assessing the strength of pairwise linkage disequilibrium (LD) between the five SNPs of the control population, we found that SNP369, SNP588, and SNP888 were not in significant LD $\left(\mathrm{r}^{2}=0.2-0.01\right)$ with any other $C X 36$ SNPs (table 2). In contrast, SNP-127 and SNP333 demonstrated a highly significant LD with each other $\left(\mathrm{r}^{2}=0.81, \mathrm{p}<0.001\right)$ (table 2). These results indicate, first, that $C X 36$ SNPs do not reside within the same LD block, and, second, that SNP-127 and 333 may be grouped to facilitate association studies, without loss of statistical power.

\section{Case control study}

To determine whether SNP333, 369, 588, and 888 were associated with JME, we tested 29 unrelated JME patients that had been shown to have a 15q14 linkage, and 140 RS JME patients. These two JME groups were analysed both separately and as a single population. The 15ql4-linked JME sample represents the largest available European set of patients whose linkage to the $15 q 14$ locus has been unambiguously established. ${ }^{627}$ Using Fisher's exact test, we found that the allele frequency of SNP588 was significantly $(p=0.03)$ different between the 15q14-linked JME group and the control group (table 1). We also found a trend towards a difference $(\mathrm{p}=0.057)$ in the allele frequency of SNP588 between the RS JME group and the control group. When all the JME patients were pooled and compared to the control group, the allele frequency of SNP588 was also significantly different $(p=0.03)$ as judged by the Fisher test, but did not reach statistical difference when a conservative correction for multiple testing was applied. This finding suggests that a small difference in the allele frequency may become masked because of the rarity of the disease. The risk of JME increased in the presence of a T allele, in both the

Table 1 Allele frequency of CX36 SNPs in JME cases and controls

\begin{tabular}{|c|c|c|c|c|c|c|c|}
\hline SNP* & Alleles, $\mathbf{n}(\%)$ & & p Valuet & Function & Protein residue & Amino acid position & dbSNP ID \\
\hline $\begin{array}{l}\text { SNP-129 } \\
15 q 14 \text { JME } \\
\text { RS JME } \\
\text { Combined } \\
\text { Control }\end{array}$ & $\begin{array}{l}A \\
N D \\
N D \\
N D \\
150(70.7)\end{array}$ & $\begin{array}{l}T \\
\text { ND } \\
\text { ND } \\
\text { ND } \\
62(29.3)\end{array}$ & $\begin{array}{l}- \\
-\end{array}$ & - & - & - & rs2277558 \\
\hline $\begin{array}{l}\text { SNP333 } \\
15 q 14 \text { JME } \\
\text { RS JME } \\
\text { Combined } \\
\text { Control }\end{array}$ & $\begin{array}{l}T^{\top} \\
44(75.9) \\
160(70.2) \\
204(71.3) \\
292(67.9)\end{array}$ & $\begin{array}{l}\mathrm{A} \\
14(24.1) \\
68(29.8) \\
82(28.7) \\
138(32.1)\end{array}$ & $\begin{array}{l}0.29 \\
0.58 \\
0.33\end{array}$ & Synonymous & Thr & 111 & rs651724 \\
\hline $\begin{array}{l}\text { SNP369 } \\
15 q 14 \text { JME } \\
\text { RS JME } \\
\text { Combined } \\
\text { Control }\end{array}$ & $\begin{array}{l}C_{56}(96.50) \\
170(89.5) \\
226(91.1) \\
211(92.5)\end{array}$ & $\begin{array}{l}T \\
2(3.5) \\
20(10.5) \\
22(8.9) \\
17(7.5)\end{array}$ & $\begin{array}{l}0.37 \\
0.3 \\
0.61\end{array}$ & Synonymous & Ser & 123 & - \\
\hline $\begin{array}{l}\text { SNP588 } \\
15 q 14 \text { JME } \\
\text { RS JME } \\
\text { Combined } \\
\text { Control }\end{array}$ & $\begin{array}{l}C \\
34(58.6) \\
181(65.1) \\
215(64) \\
179(72.8)\end{array}$ & $\begin{array}{l}\mathrm{T} \\
24(41.4) \\
97(34.9) \\
121(36) \\
67(27.2)\end{array}$ & $\begin{array}{l}\frac{0.033 \ddagger}{0.057} \\
\underline{0.026 \S}\end{array}$ & Synonymous & Ser & 196 & rs 3743123 \\
\hline $\begin{array}{l}\text { SNP888 } \\
15 q 14 \text { JME } \\
\text { RS JME } \\
\text { Combined } \\
\text { Control }\end{array}$ & $\begin{array}{l}G \\
\quad 49(84.5) \\
229(88.8) \\
278(88) \\
205(88.4)\end{array}$ & $\begin{array}{l}\mathrm{A} \\
9(15.5) \\
29(11.2) \\
38(12) \\
27(11.6)\end{array}$ & $\begin{array}{l}0.5 \\
0.88 \\
1\end{array}$ & Synonymous & Glu & 296 & - \\
\hline
\end{tabular}

ND, Not determined. dbSNP, public database reference (http://www.ncbi.nlm.nih.gov/SNP)

*SNP offset were calculated taking the A of the CX36 start codon as position 1, and using the GenBank accession no. NM_020660; tp Values computed using Fisher's exact test, give the significance value of the comparison of SNPs allele frequencies between JME and control cases. Statistically significant associations are underlined; $\neq O R=1.89 ; 95 \% \mathrm{Cl} 1.03$ to 3.45 (odds ratios and their associated $95 \% \mathrm{Cl}$ were calculated for results with $\mathrm{p}<0.05$ ); $\S \mathrm{OR}=1.5 ; 95 \% \mathrm{Cl} 1.04$ to 2.17 

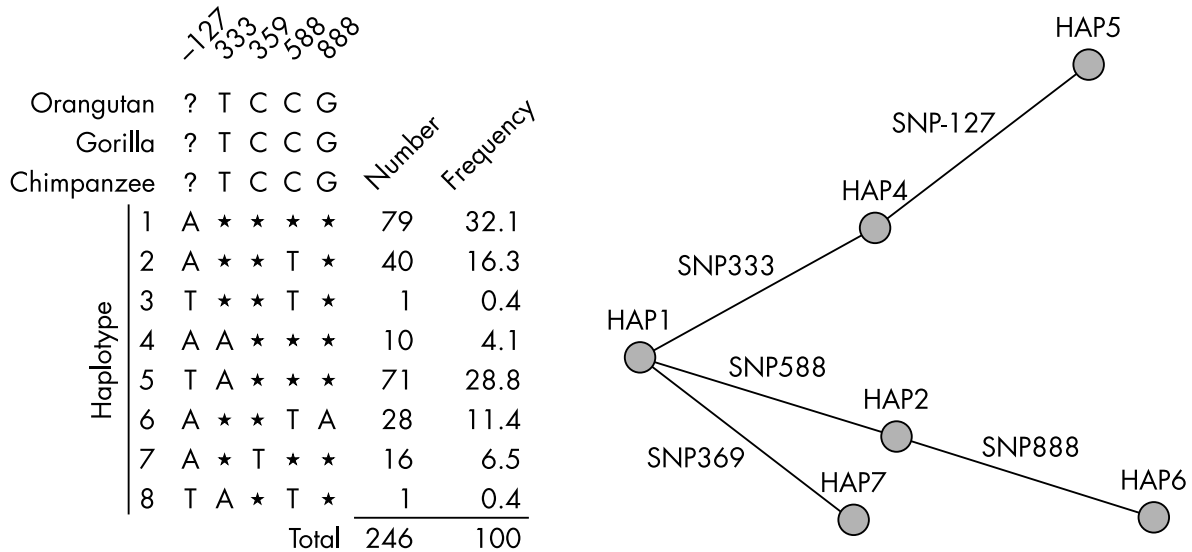

Figure 1 The haplotypes of $C \times 36$ SNPs are highly conserved in primates and derived from a common ancestor. European haplotype combinations of the CX36 gene (HAP1 to HAP8) were inferred by PHASE software in a group of 123 Caucasian control individuals. The corresponding sequences of the closely related non-human primates are also indicated. Asterisks $\left(^{*}\right)$ indicate identity of the human and ape bases. The most common CX36 haplotype (HAPI) is identical in humans and apes and, thus, likely represents the ancestral haplotype. The phylogenetic tree generated by reducedmedian-network analysis, confirmed that all other haplotypes were derived from this ancestral HAP1.

Table 2 Pairwise linkage disequilibrium $\left(r^{2}\right)$ between CX36 SNPs (unrelated controls)

\begin{tabular}{|c|c|c|c|c|}
\hline SNP & 333 & 369 & 588 & 888 \\
\hline $\begin{array}{r}-127 \\
333 \\
369 \\
588\end{array}$ & $\underline{0.81^{* \star *}}$ & $\begin{array}{l}0.03^{* *} \\
0.03^{* *}\end{array}$ & $\begin{array}{l}0.14^{* * *} \\
0.18^{\star * *} \\
0.03^{\star *}\end{array}$ & $\begin{array}{l}0.05^{\text {***}} \\
0.06^{\text {***}} \\
0.01 \\
0.32^{\text {***}}\end{array}$ \\
\hline
\end{tabular}

Significant pairwise linkage disequilibrium $\left(r^{2}>0.5\right)$ was found between SNP-127 and 333 (underlined value), but not between the three other SNPs.

${ }^{*} 0.01<p<0.05 ;{ }^{* *} 0.001<p<0.01 ;{ }^{* * *} p<0.001$

15q14-linked cases and the entire JME population $(\mathrm{OR}=1.89$ and 1.5 , respectively; table 1$)$.

We then examined the distribution of SNP588 genotypes (table 3) and found that subjects with a T/T genotype at position 588 were significantly more numerous in the $15 \mathrm{ql}$ linked JME group than in the control population $(\mathrm{OR}=4.3$; $95 \%$ CI 1.49 to $12.3, p=0.017$ ) as attested by both uncorrected and corrected tests. In addition the c.588C $>\mathrm{T}$ transition was not in HW equilibrium in the 29 linked cases' subgroup, due to an over-representation of the T/T genotype (data not shown).

\section{Haplotype association analysis}

To assess whether a combination of multiple SNPs increases the risk of JME, the frequencies of haplotypes were compared between cases and controls (table 4). The distribution of Cx36 haplotypes was significantly different $(p=0.02)$ between the 15q14-linked JME, and the control group (table 4). The haplotype TCTG, accounting for $>97 \%$ of the
Cx36 HAP2 haplotype, was more frequent in the 15q14linked JME patients than in controls $(0.28 v 0.17)$, although the difference failed to reach statistical significance. We found that homozygous carriers of the HAP2 haplotype had a significantly increased risk of JME $(p=0.03)$ than either heterozygous carriers of the HAP2 haplotype (HAP2/X) or non-carriers $(X / X)$ (table 5$)$. The same increased prevalence of the HAP2/HAP2 combination was also observed when the pooled JME group was compared to controls $(p=0.04)$.

Folding of CX36 mRNAs containing synonymous SNPs To evaluate the effect of the 588T variation, we used the MFOLD program ${ }^{28}$ to predict the structure of the mRNA coding for CX36. We observed that the predicted structure of the transcript was similar when the molecule was comprised of nucleotides 588C, 333A/588C, 369T/588C (fig 2), or -127T/ 588C (not shown), which correspond to haplotypes HAPl, HAP4, HAP7, and HAP5, respectively (fig 1). In contrast, we found that the presence of allelic variant $588 \mathrm{~T}$ caused an obvious change in the predicted structure of the CX36 mRNA, as illustrated for HAP2 (fig 2). The folding structure of the three other haplotypes containing the 588T variant (HAP3, HAP6, and HAP8) were also affected, in a similar way to that of HAP2 (not shown).

\section{Alteration of potential exonic splicing enhancers by the 588T nucleotide}

To further investigate whether the 588T variation may affect exonic splicing enhancers (ESEs), we used sequence motifscoring matrices predicting consensus functional ESE sites, ${ }^{29}$ to analyse exon 2 of wild type (HAP1) and variant (HAP2) CX36. Multiple high-score binding sites, recognised by the essential splicing factors SF2/ASF, SC35, SRp40, and SRp55,

Table 3 Genotype frequency of SNP588 in JME cases and controls

\begin{tabular}{lllllll}
\hline & \multicolumn{2}{l}{ Genotype at SNP588, $\mathbf{n}(\%)$} & & \\
\cline { 2 - 5 } Group & CC & CT & $\pi$ & Total & OR $(95 \%$ Cl)* & p Value $†$ \\
\hline 15q14 JME & $13(44.8)$ & $8(27.6)$ & $8(27.6)$ & 29 & $\frac{4.3(1.5 \text { to } 12.3)}{1.37(0.58 \text { to } 3.22)}$ & $\frac{0.017}{0.11}$ \\
RS JME & $57(41)$ & $67(48.2)$ & $15(10.8)$ & 139 & $1.79(0.81$ to 3.98$)$ & 0.09 \\
Combined & $70(41.7)$ & $75(44.6)$ & $23(13.7)$ & 168 & & \\
Control & $66(53.7)$ & $47(38.2)$ & $10(8.1)$ & 123 & &
\end{tabular}

*Odds ratio (OR) compares the T/T genotype to the pool of all other genotypes; †Given by Fisher's exact test. Statistically significant associations after Bonferroni correction are underlined. 


\begin{tabular}{|c|c|c|c|c|}
\hline Haplotype* & 15q14 JME†, n (\%) & RS JME, n (\%) & Combined, n (\%) & Control, n (\%) \\
\hline ACCG & $13(22.4)$ & 81 (28.9) & $94(27.8)$ & 81 (32.9) \\
\hline TCCG & $18(31.1)$ & $82(29.3)$ & $100(29.6)$ & 79 (32.2) \\
\hline TCTG & $16(27.6)$ & 65 (23.2) & $81(24)$ & 41 (16.7) \\
\hline TCTA & $7(12.1)$ & $32(11.4)$ & 39 (11.5) & 28 (11.4) \\
\hline TTCG & $1(1.7)$ & $20(7.2)$ & $21(6.2)$ & $16(6.5)$ \\
\hline ACTG & $1(1.7)$ & 0 & $1(0.3)$ & $1(0.3)$ \\
\hline TाCA & $1(1.7)$ & 0 & $1(0.3)$ & 0 \\
\hline TCCA & $1(1.7)$ & 0 & $1(0.3)$ & 0 \\
\hline
\end{tabular}

Table 5 Association between HAP2 haplotype combinations and JME

\begin{tabular}{|c|c|c|c|c|c|c|}
\hline \multirow[b]{2}{*}{ Group } & \multicolumn{3}{|c|}{ Haplotype HAP2, n (\%)* } & \multirow[b]{2}{*}{ Total } & \multirow[b]{2}{*}{ OR $(95 \% \mathrm{Cl}) \dagger$} & \multirow[b]{2}{*}{ p Value: } \\
\hline & HAP2/HAP2 & HAP2/X & $x / X$ & & & \\
\hline $\begin{array}{l}15 q 14 \text { JME } \\
\text { RS JME } \\
\text { Combined } \\
\text { Control }\end{array}$ & $\begin{array}{l}3(10.5) \\
6(4) \\
9(5.5) \\
1(0.8)\end{array}$ & $\begin{array}{l}10(34.5) \\
53(38) \\
63(37.5) \\
39(31.7)\end{array}$ & $\begin{array}{l}16(55) \\
81(58) \\
96(57) \\
83(67.5)\end{array}$ & $\begin{array}{r}29 \\
140 \\
168 \\
123\end{array}$ & $\begin{array}{l}\frac{14.8(1.3 \text { to } 147.5)}{5.46(0.6 \text { to } 48)} \\
6.91(0.8 \text { to } 57.6)\end{array}$ & $\begin{array}{l}\frac{0.026}{0.102} \\
\underline{0.04}\end{array}$ \\
\hline
\end{tabular}

${ }^{*} X$ denotes any haplotype other than HAP2; $†$ OR compare the HAP2/HAP2 combination to all other combinations; ‡Given by Fisher's exact test.

Statistically significant associations are underlined.

were distributed throughout this exon. We found that the $588 \mathrm{~T}$ synonymous nucleotide specifically disrupted the SF2/ ASF motif (CTCECGC) and the SC35 motif (ATCTCEGG), reducing the cognate score from 2.266 to 0.801 and from 3.176 to 1.441 , respectively. The resulting values fell below the calculated default thresholds for the native motifs (1.95 and 2.38, respectively), indicating that the $588 \mathrm{~T}$ variation rendered the SF2/ASF and SC35 ESEs inactive.
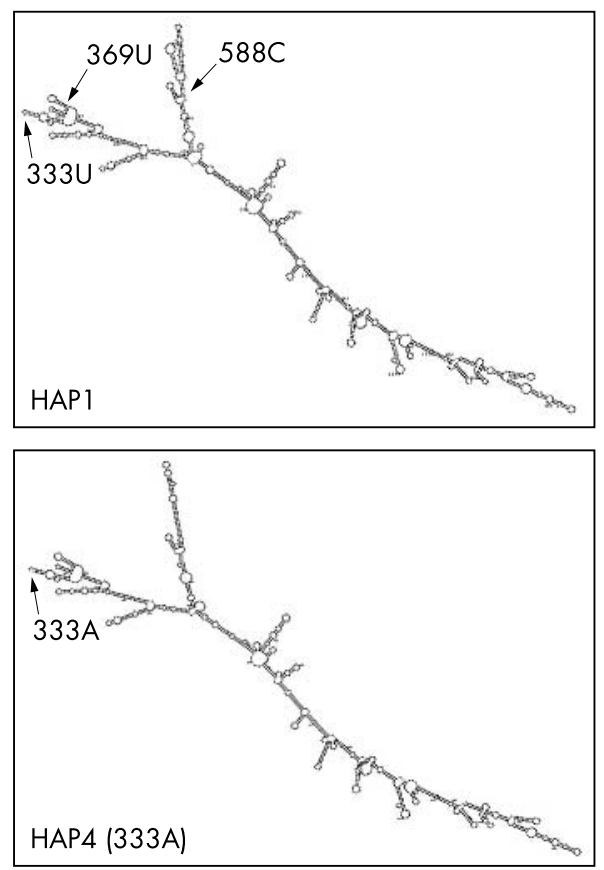

\section{DISCUSSION}

Juvenile myoclonic epilepsy is a common form of idiopathic, generalised epilepsy that shows a complex pattern of inheritance. Two major susceptibility loci, EJMI on chromosome $6 \mathrm{p} 21$ and EJM2 on chromosome 15q14, have been identified by linkage analysis. The finding of a significant linkage disequilibrium between JME and a haplotype of the $B R D 2$ gene, which is located on chromosome $6 \mathrm{p} 21$, suggested
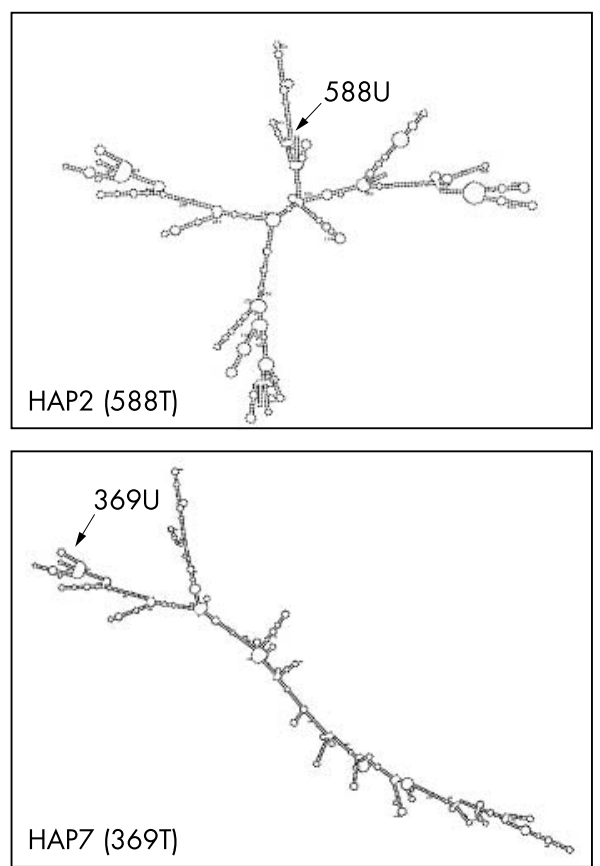

Figure 2 The predicted folding structure of $\mathrm{C} \times 36 \mathrm{mRNA}$ is altered by the 588T SNP. A sequence of $1147 \mathrm{bp}$, covering the complete coding sequence of Cx36 mRNA and including various synonymous SNPs, was tested with MFOLD software to predict the secondary structure of the transcript. The folding pattern of HAP1, the most common CX36 haplotype, was not affected by the SNPs we studied (illustrated by HAP4 and HAP7). In contrast, this structure was markedly altered in haplotypes carrying the 588T SNP, for example in HAP2. 
that BRD2 is EJM1. ${ }^{11}$ In contrast, the genes involved at the EJM2 locus are still unknown. In the present study, we screened the CX36 gene for SNPs and found that the c. $588 \mathrm{C}>\mathrm{T}$ variant, located in exon 2 , is associated with JME. In addition, we found that the homozygous combination of HAP2, one of the CX36 haplotypes containing SNP588, was significantly associated with JME. These findings suggest that $C X 36$ is a potential susceptibility gene for juvenile myoclonic epilepsy at the EJM2 locus.

The mechanisms through which SNP588C $>$ T predisposes to JME remain to be elucidated. First, it is possible that the c. 588C $>$ T transition may be a functional variant of the $C X 36$ gene, conferring susceptibility to JME. This hypothesis is supported by the finding of a $\mathrm{C}$ at position 588 in the sequence of the ancestral human CX36 haplotype (HAP1), as well as in the $C X 36$ sequence of non-human primates and phylogenetically more distant species, such as the house mouse (GenBank NM 010290.1) and the cow (GenBank NM_174683.1), indicating an evolutionary conservation of this base, which suggests a likely importance for the function of the $C X 36$ gene. In turn, the c. $588 \mathrm{C}>\mathrm{T}$ variant could alter this function, for example by affecting RNA stability. While most of the elements which control the stability of mRNAs are located in the 5'- and 3'-UTRs of genes, compelling evidence indicates the presence of other stabilising elements also in the coding region of many genes. ${ }^{3031}$ Because individual exons comprise multiple positive and negative cis elements that affect splicing, some exonic SNPs may influence splicing efficiency and, therefore, the levels of gene expression. ${ }^{32}$ The predicted changes, both in the secondary structure of Cx36 mRNA and in two potential ESEs, we observed for the synonymous SNP588C $>\mathrm{T}$ are consistent with this hypothesis. Further studies, examining the relation between mRNA stability, exon skipping, translation efficiency, and SNP588 genotype, should determine whether this variant is indeed responsible for decreased CX36 levels. Second, it is conceivable that SNP588 may be in linkage disequilibrium with other variants of the same haplotype that confer susceptibility to JME. The existence of such variants is suggested by the association of HAP2, one of the CX36 haplotypes containing SNP588, with JME. The analysis of haplotype combination showed an over-representation of this homozygous risk haplotype in the 15q14-linked patients, consistent with the LOD score maximisation previously reported at EJM2, using a recessive model. ${ }^{27}$ Increasing evidence indicates that the interaction of multiple SNPs within a haplotype can lead to functional changes. ${ }^{31}{ }^{33}$ Since SNPs occur approximately every 500-1000 bp of DNA in human chromosomes, ${ }^{34}$ several other variants are anticipated in the $5^{\prime}-, 3^{\prime}$-UTRs and intron regions of the CX36 gene. The presence of causative mutations in these regulatory regions should be further investigated. Third, our data do not exclude the possibility that the CX36 SNP associated with JME might be in linkage disequilibrium with variants of another gene, such as the ACTC gene or another gene located close to $C X 36$. However, no such gene was identified in the proximity of CX36, using the UCSC genome browser ${ }^{35}$ (not shown).

Recent studies indicate that $C X 36$ is a likely gene for JME. This gene encodes a protein making channels at electrical synapses between neurons ${ }^{12}$ and at gap junctions between the electrically excitable insulin-producing $\beta$-cells of pancreas. $^{36}$ In a previous study, we have shown that Cx36-made channels control the synchronisation of $\mathrm{Ca}^{2+}$ oscillations in a transformed cell line. ${ }^{37}$ Although no such control has yet been investigated in neuronal cells, it is consistent with a possible involvement of Cx36 in the regulation of neuronal excitability. Moreover, it has been shown that the generation of myoclonic seizures is closely associated with an abnormal synchronisation of neurons, particularly in the inferior olive, ${ }^{38}$ a brain region where Cx36 is highly expressed. ${ }^{39}$ In view of the recent findings that deletion of $C \times 36$ in mice leads to altered oscillations of interneurons in both hippocampus and neocortex, ${ }^{19} 2040$ a change in the levels of CX36 could conceivably be involved in the generation of epileptic seizures. The lack of such epilepsy events in the $C \times 36$ knock-out model ${ }^{1920} 40$ does not contradict this involvement, inasmuch as these mice may have developed several morphological and electrophysiological changes compensating for the loss of $\mathrm{C} \times 36 .{ }^{41}$ These negative findings rather indicate that the existing murine models may not be relevant for investigating the participation of Cx36 in complex diseases, such as human JME. At any rate, this is the first study which associates a genetic variation in the connexin36 gene with JME.

\section{ACKNOWLEDGEMENTS}

We are grateful to all the families who participated in the study and to Drs D Chadwick, A Sundqvist, M Kerr, A Arzimanoglou, and M Santos for help in patient ascertainment. We thank Professor Naruya Saitou and Doctor Takashi Kitano for allowing us access to unpublished data on apes, and Dr ET Dermitzakis for helpful discussion.

\section{Authors' affiliations}

C Mas, P Meda, Department of Morphology, University of Geneva Medical School, 1211 Geneva, Switzerland

S Deutsch, M Guipponi, S E Antonarakis, Division of Medical Genetics, University of Geneva Medical School, 1211 Geneva, Switzerland N Taske, M Rees, M Gardiner, Department of Pediatrics and Child Health, Royal Free and University College Medical School, The Rayne Institute, London, WCIE 6JJ, UK

P Thomas, C Buresi, A Malafosse, Department of Psychiatry, University of Geneva, 1225 Geneva, Switzerland

G P Pizzolato, Department of Pathology, University of Geneva Medical School, 1211 Geneva, Switzerland

M Friis, M J Kjeldsen, Department of Neurology, Odense University Hospital, DK-5000 Odense, Denmark

J-G Villemure, Neurosurgery Service, CHUV, 1011 Lausanne, Switzerland

A Covanis, Department of Neurology, The Children's Hospital "Agia Sophia", 11527, Athens, Greece

CM is supported by the Fondation Romande pour la Recherche sur le Diabete and the Swiss Academy of Medical Sciences (Theodore OttFund 07/01). The work of the Meda team is supported by grants from the Swiss National Foundation (3100-067788.02), the Juvenile Diabetes Research Foundation International (1-2001-622 and 5-2004-255), the European Union (QLRT-2001-01777), and the National Institute of Health (DK 63443-01). The work of the Antonarakis team is supported by grants from the Swiss National Foundation (31.57149.99), the European Union (QLG1-2002-00816) and the National Center for Competence in Research "Frontiers in Genetics". The work of the Gardiner team is supported by the UK Medical Research Council.

Conflict of interest: none declared.

*These authors contributed equally to this work.

Correspondence to: Dr Christophe Mas, Department of Morphology, University of Geneva Medical School, 1 rue Michel Servet, 1211 Geneva 4, Switzerland; Christophe.Mas@medecine.unige.ch

Received 29 December 2003

Accepted for publication 9 March 2004

\section{REFERENCES}

1 Hauser WA, Annegers JF, Rocca WA. Descriptive epidemiology of epilepsy: contributions of population-based studies from Rochester, Minnesota. Mayo Clin Proc 1996;71(6):576-86.

2 Janz D. Genetics in juvenile myoclonic epilepsy. In: Kotagal P, ed. The epilepsies: etiologies and prevention. London: Academic Press, 1999:561-70.

3 Delgado-Escueta AV, Enrile-Bacsal F. Juvenile myoclonic epilepsy of Janz. Neurology 1984;34(3):285-94. 
4 Greenberg DA, Durner M, Delgado-Escueta AV. Evidence for multiple gene loci in the expression of the common generalized epilepsies. Neurology 1992;42(4 suppl 5):56-62.

5 Berkovic SF, Howell RA, Hay DA, Hopper JL. Epilepsies in twins: genetics of the major epilepsy syndromes. Ann Neurol 1998;43(4):435-45.

6 Elmslie FV, Rees M, Williamson MP, Kerr M, Kjeldsen MJ, Pang KA, Sundqvist A, Friis ML, Chadwick D, Richens A, Covanis A, Santos M, Arzimanoglou A, Panayiotopoulos CP, Curtis D, Whitehouse WP Gardiner RM. Genetic mapping of a major susceptibility locus for juvenile myoclonic epilepsy on chromosome 15q. Hum Mol Genet 1997;6(8): 1329-34

7 Escayg A, De Waard M, Lee DD, Bichet D, Wolf P, Mayer T, Johnston J, Baloh R, Sander T, Meisler MH. Coding and noncoding variation of the human calcium-channel beta4-subunit gene CACNB4 in patients with idiopathic generalized epilepsy and episodic ataxia. Am J Hum Genet 2000;66(5): 1531-9

8 Cossette P, Liu L, Brisebois K, Dong H, Lortie A, Vanasse M, Saint-Hilaire JM Carmant L, Verner A, Lu WY, Wang YT, Rouleau GA. Mutation of GABRA1 in an autosomal dominant form of juvenile myoclonic epilepsy. Nat Genet 2002;31(2): 184-9.

9 Haug K, Warnstedt M, Alekov AK, Sander T, Ramirez A, Poser B, Maljevic S, Hebeisen S, Kubisch C, Rebstock J, Horvath S, Hallmann K, Dullinger JS, Rau B, Haverkamp F, Beyenburg S, Schulz H, Janz D, Giese B, MullerNewen G, Propping P, Elger CE, Fahlke C, Lerche H, Heils A. Mutations in $\mathrm{CLCN} 2$ encoding a voltage-gated chloride channel are associated with idiopathic generalized epilepsies. Nat Genet 2003;3:3.

10 Greenberg DA, Delgado-Escueta AV, Widelitz H, Sparkes RS, Treiman L, Maldonado HM, Park MS, Terasaki PI. Juvenile myoclonic epilepsy (JME) may be linked to the BF and HLA loci on human chromosome 6. Am J Med Genet 1988;31(1):185-92.

11 Pal DK, Evgrafov OV, Tabares P, Zhang F, Durner M, Greenberg DA. BRD2 (RING3) is a probable major susceptibility gene for common juvenile myoclonic epilepsy. Am J Hum Genet 2003;73(2):261-70.

12 Condorelli DF, Parenti R, Spinella F, Trovato Salinaro A, Belluardo N Cardile V, Cicirata F. Cloning of a new gap junction gene $(\mathrm{C} \times 36)$ highly expressed in mammalian brain neurons. Eur J Neurosci 1998;10(3):1202-8.

13 Willecke K, Eiberger J, Degen J, Eckardt D, Romualdi A, Guldenagel M, Deutsch U, Sohl G. Structural and functional diversity of connexin genes in the mouse and human genome. Biol Chem 2002;383(5):725-37.

14 Zoidl G, Dermietzel R. On the search for the electrical synapse: a glimpse at the future. Cell Tissue Res 2002;310(2):137-42.

15 Milmer WH, Braun C, Arnold M, Witte H, Taub E. Coherence of gamma-band EEG activity as a basis for associative learning. Nature 1999:397(6718):434-6

16 Rodriguez E, George N, Lachaux JP, Martinerie J, Renault B, Varela FJ. Perception's shadow: long-distance synchronization of human brain activity. Nature 1999;397(6718):430-3.

17 Gibson JR, Beierlein M, Connors BW. Two networks of electrically coupled inhibitory neurons in neocortex. Nature 1999;402(6757):75-9.

18 Tamas G, Buhl EH, Lorincz A, Somogyi P. Proximally targeted GABAergic synapses and gap junctions synchronize cortical interneurons. Nat Neurosci 2000;3(4):366-71.

19 Deans MR, Gibson JR, Sellitto C, Connors BW, Paul DL. Synchronous activity of inhibitory networks in neocortex requires electrical synapses containing connexin36. Neuron 2001;31(3):477-85.

20 Hormuzdi SG, Pais I, LeBeau FE, Towers SK, Rozov A, Buhl EH, Whittington MA, Monyer $\mathrm{H}$. Impaired electrical signaling disrupts gamma frequency oscillations in connexin 36-deficient mice. Neuron 2001;31(3):487-95

21 Sohl G, Guldenagel M, Beck H, Teubner B, Traub O, Gutierrez R, Heinemann $U$, Willecke K. Expression of connexin genes in hippocampus of kainate-treated and kindled rats under conditions of experimental epilepsy. Brain Res Mol Brain Res 2000;83(1-2):44-51.
22 Guipponi M, Thomas P, Girard-Reydet C, Feingold J, Baldy-Moulinier M Malafosse A. Lack of association between juvenile myoclonic epilepsy and GABRA5 and GABRB3 genes. Am J Med Genet 1997;74(2):150-3.

23 Alderborn A, Kristofferson A, Hammerling U. Determination of singlenucleotide polymorphisms by real-time pyrophosphate DNA sequencing. Genome Res 2000;10(8):1249-58.

24 Rozas J, Rozas R. DnaSP version 3: an integrated program for molecular population genetics and molecular evolution analysis. Bioinformatics 1999:15(2): 174-5.

25 Stephens M, Smith NJ, Donnelly P. A new statistical method for haplotype reconstruction from population data. Am J Hum Genet 2001;68(4):978-89.

26 Sankoh AJ, Huque MF, Dubey SD. Some comments on frequently used multiple endpoint adjustment methods in clinical trials. Stat Med 1997; 16(22):2529-42

27 Taske NL, Williamson MP, Makoff A, Bate L, Curtis D, Kerr M, Kjeldsen MJ Pang KA, Sundqvist A, Friis ML, Chadwick D, Richens A, Covanis A, Santos M, Arzimanoglou A, Panayiotopoulos CP, Whitehouse WP, Rees M, Gardiner RM. Evaluation of the positional candidate gene CHRNA7 at the juvenile myoclonic epilepsy locus (EJM2) on chromosome 15q13-14. Epilepsy Res 2002;49(2):157-72.

28 Zuker M. Mfold web server for nucleic acid folding and hybridization prediction. Nucleic Acids Res 2003;31(13):3406-15.

29 Cartegni L, Wang J, Zhu Z, Zhang MQ, Krainer AR. ESEfinder: a web resource to identify exonic splicing enhancers. Nucleic Acids Res 2003:31(13):3568-71

30 Gay DA, Yen TJ, Lau JT, Cleveland DW. Sequences that confer beta-tubulin autoregulation through modulated mRNA stability reside within exon 1 of a beta-tubulin mRNA. Cell 1987:50(5):671-9.

31 Duan J, Wainwright MS, Comeron JM, Saitou N, Sanders AR, Gelernter J, Gejman PV. Synonymous mutations in the human dopamine receptor D2 (DRD2) affect mRNA stability and synthesis of the receptor. Hum Mol Genet 2003; 12(3):205-16

32 Cartegni L, Chew SL, Krainer AR. Listening to silence and understanding nonsense: exonic mutations that affect splicing. Nat Rev Genet 2002;3(4):285-98.

33 Drysdale CM, McGraw DW, Stack CB, Stephens JC, Judson RS, Nandabalan K, Arnold K, Ruano G, Liggett SB. Complex promoter and coding region beta 2-adrenergic receptor haplotypes alter receptor expression and predict in vivo responsiveness. Proc Natl Acad Sci U S A 2000;97(19): 10483-8.

34 Reich DE, Cargill M, Bolk S, Ireland J, Sabeti PC, Richter DJ, Lavery T, Kouyoumjian R, Farhadian SF, Ward R, Lander ES. Linkage disequilibrium in the human genome. Nature 2001:411(6834):199-204.

35 Kent WJ, Sugnet CW, Furey TS, Roskin KM, Pringle TH, Zahler AM, Haussler D. The human genome browser at UCSC. Genome Res 2002;12(6):996-1006

36 Serre-Beinier V, Le Gurun S, Belluardo N, Trovato-Salinaro A, Charollais A Haefliger JA, Condorelli DF, Meda P. Cx36 preferentially connects beta-cells within pancreatic islets. Diabetes 2000;49(5):727-34.

37 Calabrese A, Zhang M, Serre-Beinier V, Caton D, Mas C, Satin LS, Meda P. Connexin 36 controls synchronization of $\mathrm{Ca}^{2+}$ oscillations and insulin secretion in MIN6 cells. Diabetes 2003;52(2):417-24.

38 Welsh JP, Chang B, Menaker ME, Aicher SA. Removal of the inferior olive abolishes myoclonic seizures associated with a loss of olivary serotonin. Neuroscience 1998;82(3):879-97.

39 Belluardo N, Trovato-Salinaro A, Mudo G, Hurd YL, Condorelli DF. Structure, chromosomal localization, and brain expression of human $\mathrm{C} \times 36$ gene. J Neurosci Res 1999:57(5):740-52.

40 Buhl DL, Harris KD, Hormuzdi SG, Monyer H, Buzsaki G. Selective impairment of hippocampal gamma oscillations in connexin-36 knock-out mouse in vivo. J Neurosci 2003;23(3):1013-8

41 Zeeuw D, Harris KD, Hormuzdi SG, Monyer H, Buzsaki G. Deformation of network connectivity in the inferior olive of connexin 36-deficient mice is compensated by morphological and electrophysiological changes at the single neuron level. J Neurosci 2003;23(11):4700-11. 